\title{
Evaluation of a Disease Warning System for Downy Mildew of Grapes
}

\author{
L. V. Madden and M. A. Ellis, Department of Plant Pathology, Ohio State University, Wooster 44691-4096; N. \\ Lalancette, Rutgers University R \& E Center, Bridgeton, NJ 08302; G. Hughes, University of Edinburgh, West \\ Mains Road, Edinburgh EH9 3JG, Scotland; and L. L. Wilson, Department of Plant Pathology, Ohio State Univer- \\ sity, Wooster 44691-4096
}

\begin{abstract}
Madden, L. V., Ellis, M. A., Lalancette, N., Hughes, G., and Wilson, L. L. 2000. Evaluation of a disease warning system for downy mildew of grapes. Plant Dis. 84:549-554.

An electronic warning system for grape downy mildew-based on models for the infection of leaves of Vitis lambrusca, production of sporangia by Plasmopara viticola in lesions, and sporangial survival-was tested over 7 years in Ohio. Grapevines were sprayed with metalaxyl plus mancozeb (Ridomil MZ58) when the warning system indicated that environmental conditions were favorable for sporulation and subsequent infection. Over the 7 years, plots were sprayed from one to four times according to the warning system, and from four to 10 times according to the standard calendar-based schedule (depending on the date of the initiation of the experiment). The warning system resulted in yearly reductions of one to six sprays (with median of three sprays). Disease incidence (i.e., proportion of leaves with symptoms) in unsprayed plots at the end of the season ranged from 0 to $86 \%$, with a median of $68 \%$. Incidence generally was very similar for the warning-system and standard-schedule treatments (median of $7 \%$ of the leaves with symptoms), and both of these incidence values were significantly lower $(P<0.05)$ than that found for the unsprayed control, based on a generalized-linear-model analysis. Simplifications of the disease warning system, where sprays were applied based only on the infection or sporulation components of the system, were also effective in controlling the disease, although more fungicide applications sometimes were applied. Effective control of downy mildew, therefore, can be achieved with the use of the warning system with fewer sprays than a with a standard schedule.
\end{abstract}

Additional keywords: disease aggregation, disease forecasting, environmental epidemiology, integrated disease management, overdispersion

Downy mildew, caused by Plasmopara viticola, is an economically important disease of grape (Vitis spp.) in many parts of the world (27). The disease, which affects both leaves and fruit, is especially serious in climates with abundant rainfall, high relative humidity, and long periods of wetness on leaves and fruits. In Ohio, downy mildew is one of the major constraints to grape production (7).

Disease management of downy mildew in most geographic areas generally requires the use of fungicides applied several times during the growing season, starting as early as Eichhorn-Lorenz growth stage 17 (27) on highly susceptible cultivars such as Chancellor $(7,10)$. Because of the cost of such frequent applications of fungicide and the desire to reduce pesticide levels in the environment, considerable efforts have been made to develop prediction or warning systems for this disease $(8,23,25)$. If

Corresponding author: L. V. Madden

E-mail: madden.1@osu.edu

Accepted for publication 16 January 2000.

Publication no. D-2000-0313-07R

(C) 2000 The American Phytopathological Society effective, these warning systems would identify periods when conditions are favorable for disease development, and schedule fungicide applications when needed (21). The systems developed to date for grape downy mildew are based on: (i) a detailed simulation of the disease cycle $(6,23$, 25,26); (ii) simplified models of one or more components of the disease cycle (e.g., infection, sporulation, overwintering) that can be used to predict a relative risk of disease development $(8,17)$; or (ii) entirely empirical models based on long-term climatic conditions, with little direct appraisal of the disease cycle $(28,31)$. Some of the warning systems are, or have been, sold commercially as electronic predictive units (e.g., EnviroCaster) (8). An alternative to these forecasting approaches is the expert system developed by Travis et al. (30) to make management decisions about downy mildew based on several vineyard factors.

Most of the downy mildew warning systems either were developed directly for use with European grapes (Vitis vinifera) $(17,23,25)$, or major components of the systems were developed using experimental results for $V$. vinifera. The results of Blaeser and Weltzien $(2,3)$ on environmental effects on infection and sporulation have heavily influenced many of the pro- posed forecasting systems. However, the precise relationship between environmental factors, such as temperature, wetness duration, and relative humidity, and resulting infection or sporulation depends on the grape species or hybrid. For instance, the American grape, V. lambrusca, is less susceptible than $V$. vinifera (12). Typically, it takes a longer duration of leaf wetness or period of high relative humidity (RH) for infection or fungal sporulation with $V$. lambrusca than with $V$. vinifera $(19,20)$. The downy mildew warning system developed by Neogen, Inc. $(1,8)$ specifically uses published models of Lalancette et al. $(19,20)$ for infection of $V$. lambrusca and sporulation of the fungus on infected $V$. labrusca. Unlike some other published warning systems (25), the Neogen approach does not predict or assess the overwintering of oospores and their maturation in the spring, nor does it attempt to model all components of the disease cycle. Thus, primary inoculum is assumed to be available for infecting leaves when the system is in operation.

The warning system based on the models of Lalancette et al. $(19,20)$ had not been thoroughly tested in the field to determine if disease forecasting can be used to efficiently manage this disease under midwestern U.S. climatic conditions. Thus, the objective of this study was to evaluate the warning system in an experimental vineyard over several years in Ohio. For each year of testing, the number of fungicide spray applications and disease incidence for treatments following the recommendations of the warning system were compared with sprays and disease incidence for treatments not sprayed and treatments that followed a standard protectant fungicide schedule.

\section{MATERIALS AND METHODS}

Disease warning system. The warning system, as incorporated into the Neogen EnviroCaster, is primarily based on controlled-environment results for infection of $V$. lambrusca 'Catawba' by $P$. viticola $(18,19)$ and sporulation of the pathogen on infected Catawba plants (20), as well as some results for sporangial survival published by Blaeser and Weltzein $(2,3)$. Lalancette et al. (19) determined the infection efficiency ( $i$; number of lesions produced per zoospore) as a function of temperature $(T)$ and leaf wetness duration $(W)$, 
and developed a nonlinear model to predict $i$ in relation to $T$ and $W$. Lalancette et al. (20) also determined sporangial production per unit area of lesion $(s)$ in relation to temperature and duration of high $\mathrm{RH}$ ( $\geq 92 \%$ ) during darkness, and characterized the relationship with another nonlinear model. For any given time period (i.e., wetness or high RH), both $i$ and $s$ can be predicted, as well as the percentages that $i$ and $s$ are relative to their maxima under the most favorable environmental conditions. These percentages are labeled $i_{0}$ and $s_{0}$.

The EnviroCaster continuously monitors ambient temperature, RH, wetness, and rainfall, and stores totals or averages as needed for various predictive (warning) models. For downy mildew, the model's software keeps track of all nightly periods of high $\mathrm{RH}(\geq 92 \%)$ and determines the mean temperature for each period. Darkness is determined by day of year, hemisphere, and the site's latitude and longitude (1). Predicted sporulation and the percentage of the maximum sporulation are determined for each nightly sporulation period based on the previously developed nonlinear model (20). Once darkness ends, or RH goes below $92 \%$, sporangia are considered to die at a rate dependent on temperature and vapor pressure deficit (calculated from the RH). Because this rate is not known for sporangia produced on plants of $V$. lambrusca, results of Blaeser and Weltzien (3) were used to quantify spore mortality as an exponential survival function. In general, the rate of decline in sporangial population increases with temperature and vapor pressure deficit. Up to 12 sporulation-period results are stored in the EnviroCaster; when a new period is recorded, the twelfth oldest value is deleted.

At the time of an infection period (see below), the total spore load $\left(S_{0}\right)$ is calculated based on the $s_{0}$ values for the prior 12 sporulation periods after the $s_{0}$ predictions are adjusted for sporangial mortality. A different adjustment for each sporulation period is made, since the time interval is different between the end of each sporulation period and the infection period. With the high mortality of sporangia, few predicted sporangia survive more than 2 to 3 days. The value of $S_{0}$ is an index of the inoculum available for infection when an infection period occurs. Predicted $S_{0}$ is categorized as low $\left(S_{0} \leq 25 \%\right)$, moderate $\left(25 \%<S_{0} \leq 50 \%\right)$, or high $\left(S_{0}>50 \%\right)$.

When a leaf-wetness period occurs, the predicted $i$ (and $i_{0}$ ) is calculated based on $W$ and average $T$ during the period (19). Infection periods can occur during night or day. If a wetness period is interrupted by one or more dry periods (each $<4 \mathrm{~h}$ in duration), then the periods are combined to determine total $W$. Predicted $i_{0}$ is categorized as low $\left(i_{0} \leq 25 \%\right)$, moderate $(25 \%<$ $\left.i_{0} \leq 50 \%\right)$, or high $\left(i_{0}>50 \%\right)$.

In nominal use of the warning system, a fungicide application is recommended if $i_{0}$ and $S_{0}$ are both categorized as moderate or high, and it has been at least 14 days since the most recent application. A user of the system can also specify a high vineyard risk when there is evidence for high inoculum levels or very susceptible varieties. Then a fungicide application is recommended if $i_{0}$ is moderate or high at any value of $S_{0}$.

Field experiments and fungicide applications. Vineyards at the Ohio Agricultural Research and Development Center, Wooster, were used for the field experimentation. In 1989 to 1991, a vineyard of V. lambrusca 'Catawba' (planted in 1975) was utilized; in 1992 to 1995 , a vineyard of V. labrusca 'Reliance' (planted in 1989) was used. Both cultivars are susceptible to downy mildew (10). Spacing was $2.1 \mathrm{~m}$ between vines within rows, and there were $3 \mathrm{~m}$ between rows. There were three to six treatments (depending on the year) in each of three blocks, which were arranged in a randomized complete block design. Except for 1994 and 1995, experimental units consisted of three adjacent vines separated by a single untreated vine. In 1994 and 1995, experimental units consisted of single vines, each separated by an untreated vine.

In all years, at least the following three treatments were tested: (i) an unsprayed control; (ii) a full-schedule fungicide program, in which plants were sprayed every 10 to 14 days; and (iii) spraying when nominal use of the warning system indicated that a spray application was needed and at least 14 days had elapsed since the previous fungicide application (Table 1). Generally, metalaxyl plus mancozeb (metalaxyl 10\% plus mancozeb $48 \%$ [Ridomil MZ58, Novartis Crop Protection, Inc., Greensboro, NC]) was used with the warning-system treatment, and either $\mathrm{Ri}$ domil MZ58 or captan (Captan 50W, Micro Flo Co., Lakeland, FL) was used with the full-schedule program. Both are considered effective for controlling downy mildew (10). In 1989 and 1990, Ridomil MZ58 was used for all fungicide treatments. Additional treatments were evaluated in most years to consider variations of the warning system or other calendar-based fungicide programs.

In 1989, additional treatments were: (i) spray when the warning system indicated high infection and high spore load; (ii) spray when the warning system indicated moderate infection and ignore the spore load prediction; and (iii) spray when the warning system indicated high infection and ignore spore load. When the spore load component was ignored, it was possible to determine if a simpler warning model, based solely on infection conditions, could be effective for disease management. In 1990, the following additional treatments were evaluated: (i) spray when the warning system indicated high infection and spore load; (ii) spray when the warning system indicated high infection and ignore spore load component of the model; and (iii) spray when spore load was high and ignore infection predictions. In this last treatment, another simplified version of the warning system was tested; that is, spraying plants when predicted spore load was high would ensure that fungicide was applied before infection occurred (assuming the model was correct).

Starting in 1991, Captan 50WP was used in the standard full-schedule treatment and in some other treatments. The additional treatments in 1991 were: (i) an extended (21-day) fungicide schedule (Ridomil); (ii) spray with Captan when the warning system indicated high infection and spore load; and (iii) spray with Captan when the warning system indicated high spore load and ignore infection. In 1992, the additional treatments were: (i) an extended (21day) fungicide schedule; (ii) spray with Captan when the warning system indicated high infection and spore load; and (iii) spray with Captan when the warning system indicated high spore load and ignore infection. In 1993 and 1995, only the three regular treatments were tested. In 1994, an extended 21-day fungicide schedule (Ridomil MZ58) was also evaluated.

In all years of testing, Ridomil MZ58 was applied at $2.2 \mathrm{~kg} / \mathrm{ha}$ (metalaxyl at 224 $\mathrm{g}$ a.i./ha plus mancozeb at $1,075 \mathrm{~g}$ a.i./ha) of product in water (1,870 liters/ha), and Captan 50WP was applied at $4.5 \mathrm{~kg} / \mathrm{ha}$ $(2.25 \mathrm{~kg}$ a.i./ha) of product in water $(1,870$ liters/ha).

Disease assessment. Incidence of leaves with downy mildew symptoms (disease incidence) was determined at least once per season, and typically twice. Except for the first year of the study (1989), all disease assessments were made during the latter part of the growing season (after 18 August) when incidence in the control plots potentially was high. In 1989, an early assessment was made on the initiation date of the experiment to determine if disease incidence was already high by this date.

For each disease assessment before the 1994 study, leaves on five randomly chosen shoots on each of three vines per plot were observed for downy mildew lesions. The shoots were not necessarily the same for the two different assessments in the years with more than one sampling. The number of leaves with at least one lesion and the total number of leaves were recorded for each shoot. This resulted in 15 (three vines $\times$ five shoots per vine) incidence values per treatment-replicate plot. This is a form of cluster sampling as discussed in Hughes et al. (16). In 1994 and 1995 , leaves on 10 randomly chosen shoots on the single vine for each plot were observed for lesions. Downy mildew incidence was calculated as the proportion of leaves with lesions in each plot (combination of treatment and block). 
Statistical analysis. The effects of treatment on downy mildew incidence were determined with a generalized linear model (GLM) (5). A separate analysis was done for each disease assessment of each year. The GLM analysis served the same purpose as analysis of variance (which is, in fact, a special case of GLM), but it explicitly accounted for the binary aspect of disease incidence (i.e., each leaf is diseased or not) and for distribution of diseased leaves per shoot (15).

For the GLM analysis, the proportion of diseased leaves in treatment $t$ and block $j$, $y_{t j}$, was considered to be an estimate of the expected probability of a leaf being dis- eased, $p_{t j}$. The logit link function (transformation) was used, and it was assumed, initially, that the diseased leaves per plot had a binomial distribution. Using the methods presented in Hughes and Madden (15), aggregation or clustering of disease incidence (i.e., overdispersion [5]) was determined by comparison of the deviance from the chosen full model (treatment + block effects) with the residual degrees of freedom. (The deviance is analogous to the residual sum of squares with analysis of variance.) To correct for overdispersion, the quasi-likelihood (moment) method of Moore (24), as discussed by Hughes and Madden (15), was used. This enabled more accurate determination of the standard errors of estimated parameters (such as expected probability of a diseased leaf). The Moore method incorporated the binary power-law relationship between the observed variance of $y_{t j}$ and theoretical variance for a random (binomial) distribution, which we previously demonstrated to be appropriate for downy mildew incidence data (22). The analysis used here corresponded to Model E in Hughes and Madden (15), which is one appropriate method for the situation in which aggregation of disease incidence depends on the level of incidence. The Moore correction essentially consists of using weights in the

Table 1. Summary of fungicide application schedules, fungicides used, date of first spray application, number of applications, and leaf disease incidence in experiments testing the warning system for downy mildew of grapes

\begin{tabular}{|c|c|c|c|c|c|}
\hline $\begin{array}{l}\text { Year } \\
\text { Treatment }^{\mathrm{a}}\end{array}$ & Fungicide $^{b}$ & $\begin{array}{c}\text { First spray } \\
\text { (mo/day) }\end{array}$ & $\begin{array}{c}\text { Spray } \\
\text { applications }\end{array}$ & \multicolumn{2}{|c|}{ Mean disease incidence ${ }^{c}$} \\
\hline 1989 (1 July) $^{d}$ & & & & 1 July & 14 September \\
\hline 1) Standard schedule (14-day) & Ridomil MZ58 & $7 / 11$ & 4 & $0.029(0.011)$ & $0.013(0.006)$ \\
\hline 2) Model (spray advised) & Ridomil MZ58 & $7 / 31$ & 1 & $0.057(0.016)$ & $0.112(0.018)^{*} \mathrm{e}$ \\
\hline 3) Model (high infection and high spore load) & Ridomil MZ58 & $7 / 31$ & 1 & $0.012(0.007)$ & $0.028(0.009)$ \\
\hline 4) Model (moderate infection, ignore spore load) & Ridomil MZ58 & $7 / 28$ & 2 & $0.028(0.011)$ & $0.017(0.008)$ \\
\hline 5) Model (high infection, ignore spore load) & Ridomil MZ58 & $7 / 31$ & 2 & $0.048(0.015)$ & $0.018(0.007)$ \\
\hline 6) Unsprayed control & - & - & 0 & $0.022(0.009)$ & $0.685(0.026)^{*}$ \\
\hline 1990 (15 May) & & & & 28 August & 30 September \\
\hline 1) Standard schedule (14-day) & Ridomil MZ58 & $5 / 23$ & 9 & $0.021(0.008)$ & $0.026(0.009)$ \\
\hline 2) Model (spray advised) & Ridomil MZ58 & $6 / 7$ & 4 & $0.027(0.009)$ & $0.075(0.015)^{*}$ \\
\hline 3) Model (high infection and spore load) & Ridomil MZ58 & $6 / 7$ & 4 & $0.048(0.012)$ & $0.042(0.011)$ \\
\hline 4) Model (high infection, ignore spore load) & Ridomil MZ58 & $5 / 19$ & 7 & $0.024(0.008)$ & $0.035(0.010)$ \\
\hline 5) Model (ignore infection, high spore load) & Ridomil MZ58 & $6 / 7$ & 4 & $0.099(0.017)^{*}$ & $0.075(0.015)^{*}$ \\
\hline 6) Unsprayed control & - & - & 0 & $0.500(0.009)^{*}$ & $0.668(0.028)^{*}$ \\
\hline 1991 (30 May) & & & & & 15 September \\
\hline 1) Standard protectant (10- to 14 day) & Captan 50WP & $6 / 12$ & 10 & & 0 \\
\hline 2) Model (spray advised) & Ridomil MZ58 & $6 / 24$ & 4 & & 0 \\
\hline 3) Model (high infection and spore load) & Captan 50WP & $6 / 24$ & 5 & & 0 \\
\hline 4) Model (ignore infection, high spore load) & Captan 50WP & $6 / 18$ & 6 & & 0 \\
\hline 5) Extended schedule (21-day) & Ridomil MZ58 & $6 / 12$ & 5 & & 0 \\
\hline 6) Unsprayed control & - & - & 0 & & 0 \\
\hline 1992 (23 June) & & & & 19 August & 22 September \\
\hline 1) Standard protectant (10- to 14 day) & Captan 50WP & $6 / 23$ & 9 & $0.126(0.023)$ & $0.197(0.022)$ \\
\hline 2) Model (spray advised, 14 days) & Ridomil MZ58 & $7 / 18$ & 3 & $0.095(0.020)$ & $0.154(0.020)^{*}$ \\
\hline 3) Model (high infection and spore load, 10 days) & Captan 50WP & $7 / 18$ & 3 & $0.153(0.026)$ & $0.165(0.021)$ \\
\hline 4) Model (ignore infection, high spore load) & Captan 50WP & $7 / 6$ & 5 & $0.199(0.030)^{*}$ & $0.246(0.025)^{*}$ \\
\hline 5) Extended schedule (21 day) & Ridomil MZ58 & $6 / 23$ & 5 & $0.031(0.010)^{*}$ & $0.068(0.014)^{*}$ \\
\hline 6) Unsprayed control & - & - & 0 & $0.409(0.039)^{*}$ & $0.864(0.019)^{*}$ \\
\hline 1993 (1 July) & & & & & 8 September \\
\hline 1) Standard protectant (14 day) & Captan 50WP & $7 / 1$ & 5 & & 0 \\
\hline 2) Model (spray advised) & Ridomil MZ58 & $7 / 1$ & 3 & & 0 \\
\hline 3) Unsprayed control & - & - & 0 & & 0 \\
\hline 1994 (1 July) & & & & & 30 August \\
\hline 1) Standard protectant (14 day) & Captan 50WP & $7 / 8$ & 5 & & $0.008(0.003)$ \\
\hline 2) Model (spray advised) & Ridomil MZ58 & $7 / 15$ & 4 & & $0.006(0.003)$ \\
\hline 3) Extended schedule (21 day) & Ridomil MZ58 & $7 / 8$ & 4 & & $0.005(0.003)$ \\
\hline 4) Unsprayed control & - & - & 0 & & $0.561(0.029)^{*}$ \\
\hline 1995 (30 June) & & & & & 30 August \\
\hline 1) Standard protectant (14 day) & Captan 50W & $6 / 30$ & 5 & & $0.298(0.036)$ \\
\hline 2) Model (spray advised) & Ridomil MZ58 & $6 / 30$ & 4 & & $0.070(0.017)^{*}$ \\
\hline 3) Unsprayed control & - & - & 0 & & $0.855(0.026)^{*}$ \\
\hline
\end{tabular}

${ }^{a}$ Unless indicated otherwise, fungicide applications are never more frequent than every 14 days, even if favorable environmental conditions occurred.

${ }^{\mathrm{b}}$ Unless indicated otherwise, Ridomil MZ58 was applied at $2.2 \mathrm{~kg} / \mathrm{ha}$ of product (metalaxyl at $224 \mathrm{~g}$ a.i./ha plus mancozeb at $1,075 \mathrm{~g}$ a.i./ha) in water (1,870 liters/ha), and Captan 50WP was applied at $4.5 \mathrm{~kg} / \mathrm{ha}$ of product $(2.25 \mathrm{~kg}$ a.i./ha) in water $(1,870$ liters/ha).

${ }^{\mathrm{c}}$ Incidence was the mean proportion of leaves with symptoms of downy mildew, with the standard errors in parentheses. Except for 1994 and 1995 , all leaves on five randomly selected shoots on each of three vines (i.e., 15 shoots, total of 8 to 20 leaves per shoot) were assessed for symptoms on the indicated dates in each treatment of each block. Mean incidence is an estimate of the expected probability of a leaf being diseased.

${ }^{\mathrm{d}}$ Number in parentheses following year is the date (mo/day) that the experiment began. Treatment 2 corresponds to nominal use of the warning system in each year.

${ }^{\mathrm{e}}$ Means of incidence followed by an asterisk are significantly different $(P \leq 0.05)$ (higher or lower) from treatment 1 within a year and assessment time. Except for 1 July 1989 (which was before any fungicide applications), the control mean was always significantly different from all other treatments $(P=$ 0.05 ) when there was nonzero incidence. 
analysis, with the weights being a function of the degree of overdispersion, quantified, in part, by an estimated parameter, $\xi$ (see equation 9 in Hughes and Madden [15]). Values of $\xi$ greater than 1 indicate that the degree of overdispersion (disease aggregation) depends on the probability of a leaf being diseased; $\xi$ is analogous to $b$ of the binary power law, which has previously been shown to describe the aggregation of downy mildew in the 1989, 1990, and 1992 data sets (22). The GLIM software package was used for all analyses (14).

Based on the predicted logit (linear predictor in the GLM notation) for each treatment and its standard error, the esti- mated probability of a leaf being diseased $\left(\hat{p}_{t}\right)$ and its standard error were determined (5). The value of $\hat{p}_{t}$ was equivalent to the mean leaf disease incidence, and we use incidence or mean incidence interchangeably with $\hat{p}_{t}$ in the text. Comparison among the mean responses for pairs of treatments was based on differences in $\hat{p}_{t}$ and the calculated standard error of the differences.

For some comparisons of treatments, the relative risk of disease $(\rho)$ was also calculated (5), which equals the ratio of two $\hat{p}_{t}$ values. For example, the $\rho$ value for the control in relation to the warning system $\left(\rho_{c / w}\right)$ was estimated as the ratio of their incidence values; $\rho_{c / w}$ here is a measure of
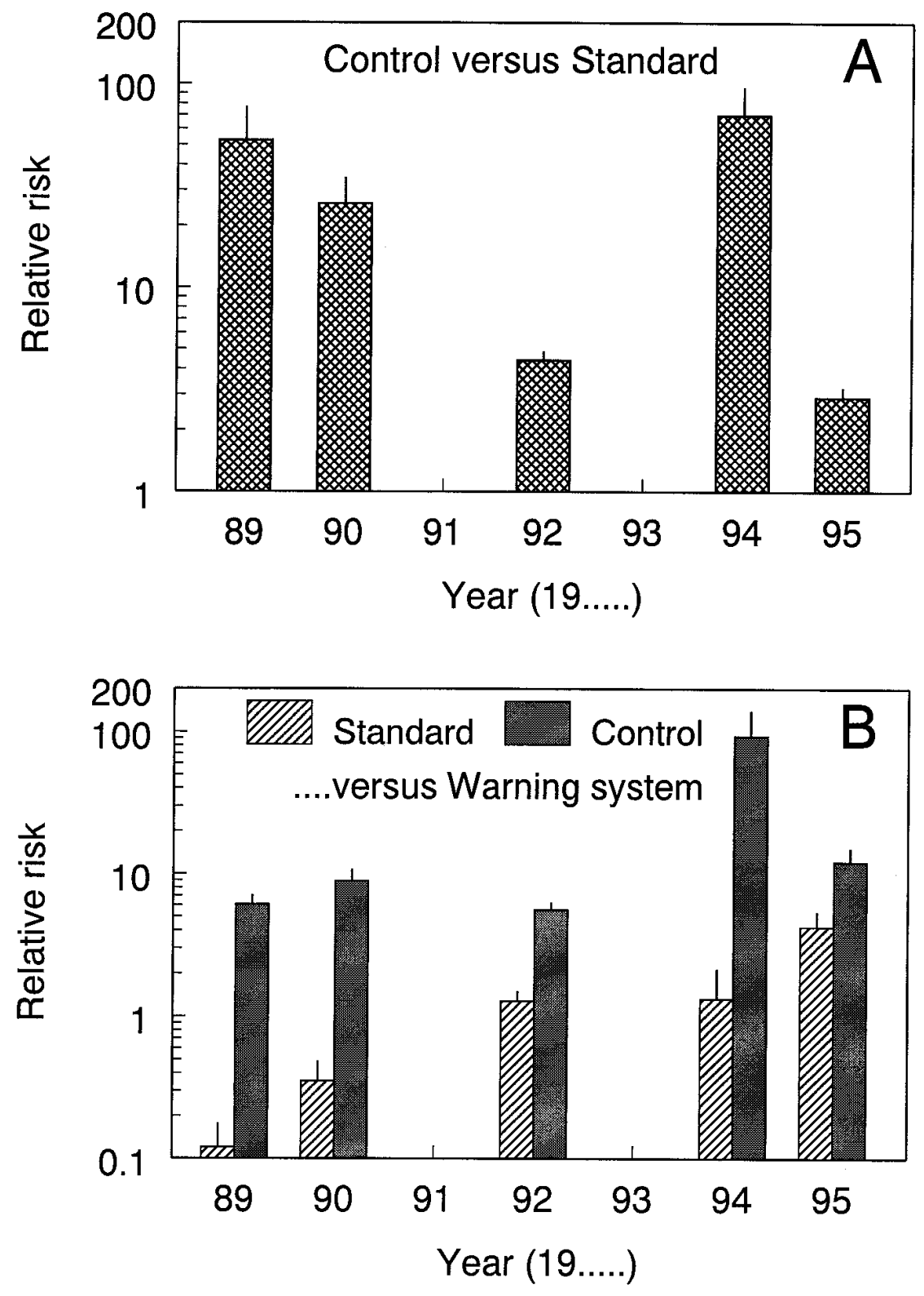

Fig. 1. Relative risk of grape downy mildew, caused by Plasmopara viticola, over 7 years of fieldtesting of fungicide applications, scheduled on a calendar-basis (standard), the disease-warning system, or not sprayed (control). Relative risk is the ratio of two estimated probabilities of a leaf being diseased. (A) Disease risk for the control relative to the standard treatment $\left(\rho_{c / s}\right)$. (B) Disease risk for the standard treatment and control both relative to the disease-warning treatment $\left(\rho_{s / w}\right.$ and $\left.\rho_{c / w}\right)$. Vertical lines are estimated standard errors of the relative risks (5). Relative risk is undefined when estimated probability in the denominator is zero (see 1991 and 1993).

the extent to which a leaf that is not sprayed is more (or less) likely to become diseased than a leaf that is sprayed through the season according to the warning system (5).

\section{RESULTS}

Unsprayed vines. In 2 years (1991 and 1993), no diseased leaves were observed. In 5 of the 7 years of this study, however, percentage of leaves with downy mildew symptoms was over $50 \%$ on the final assessment date (Table 1). Disease incidence was over $80 \%$ in two of these years (1992 and 1995). Incidence was observed to increase over time in all the years when more than one assessment was made (1989, 1990, and 1992).

Generalized linear model analysis. Based on the GLM analysis for all years that had nonzero leaf disease incidence, treatment had a significant $(P<0.05)$ effect on final downy mildew incidence (Table 1). Treatment also had a significant $(P<0.05)$ effect on the disease for the first assessment dates (in the years with two assessments), except for the first assessment in 1989. This exception corresponded to a disease assessment before any fungicide sprays were applied and all incidence means being less than $6 \%$.

All data sets of disease incidence exhibited significant aggregation or overdispersion (22), as indicated by large deviances relative to the residual degrees of freedom. The variable aggregation method of Moore (24), corresponding to Model E in Hughes and Madden (15), successfully corrected for this overdispersion. Estimates of the $\xi$ parameter for the relationship between overdispersion and probability of disease were generally greater than 1 for all data sets. After the Moore (24) method was applied, estimates of the within-plot deviance were roughly equal to the degrees of freedom, indicating that the method corrected for disease aggregation.

Fungicide effects. All fungicide spray programs were effective in reducing downy mildew incidence (Table 1 ) in the 5 years where there were observed symptoms of downy mildew. Incidence was always less than $30 \%$ with the standard fungicide schedule (treatment 1 ; i.e., $\hat{p}_{1}<$ 0.30 ). In 3 of 5 years, final incidence was less than 5\% for this treatment. However, in the final year of this study (1995), nearly three of 10 leaves had symptoms of downy mildew on 30 August. The years with high incidence values for this treatment also had the highest incidence in the unsprayed control plots (Table 1). The relative risk of disease (5) in the absence of fungicide applications in relation to the standard fungicide schedule $\left(\rho_{c / s}\right)$ was calculated as $\hat{p}$ for the control (e.g., $\hat{p}_{6}$ in 1989) divided by $\hat{p}_{1}$. The estimated values of $\rho_{c / s}$ ranged from 3 to 80 (Fig. 1A), meaning that a diseased leaf on unsprayed vines was 3 to 80 times more likely to occur than a dis- 
eased leaf on vines sprayed according to the standard fungicide schedule. Depending on the year and the initiation time of the experiment, between four and 10 fungicide applications were applied for the standard spray schedule (Table 1) to achieve disease control. The wide range in number of sprays was due to variation in the start of the experiments among years.

In the years where an extended (21-day) fungicide schedule was tested and disease was observed (treatment 5 in 1992 and treatment 3 in 1994), disease control was as good as the more intensive (10- to 14day) standard schedule (treatment 1). In fact, incidence was lower in 1992 for the extended schedule compared with the standard, likely because the fungicides were different between these two treatments. Ridomil MZ58 was applied to plants for the extended schedule, whereas Captan 50WP was applied for the standard schedule.

Disease warning system. Mean disease incidence was low in the plots that were sprayed based on the nominal use of the warning system (see treatment 2 in Table 1). Highest final disease incidence was $15 \%$ for this treatment (1992), and incidence was less than $8 \%$ in 3 of 5 years. One can see the effects of following the warning system by the calculated relative risk of downy mildew in the control compared with the warning system $\left(\rho_{c / w}\right)$. Estimated $\rho_{c / w}$ values were all substantially greater than 1 (Fig. 1B, solid bars). The relative risk ranged from $\sim 6$ to 100 , meaning that a diseased leaf was 6 to 100 times more likely to occur on an unsprayed vine than on a vine sprayed based on nominal use of the downy mildew warning system.

In some years, mean disease incidence for the warning-system treatment was significantly less than for the standard fungicide schedule (1992 and 1995). In these 2 years, different fungicides were used for these two treatments (Table 1); thus, differences can be attributed to timing of fungicide applications and possible differential effectiveness of the fungicides. Estimated $\rho$ values for the standard fungicide treatment versus the warning-system treatment $\left(\rho_{s / w}\right)$ were slightly greater than 1 for these 2 years (Fig. 1B, hatched bars). In some other years where Ridomil MZ58 was used for all treatments (1989 and 1990), incidence was lower for the standard fungicide schedule compared with the warning system. This is indicated by the estimated $\rho_{s / w}$ values being less than 1 for these 2 years (Fig. 1B). Number of fungicide applications based on the warning system was either three or four, except for 1989 , in which there was only one spray applied.

Variations in use of the warning system. Additional spray treatments based on the selected output of the warning system generally gave acceptable control of downy mildew (Table 1). As expected, when vines were sprayed based solely on the infection predictions of the system, more spray applications were predicted. For example, seven sprays were applied in 1990 for the treatment based just on infection predictions, compared with four sprays for the nominal use of the warning system (Table 1). This infection-only use of the warning system resulted in equal or lower disease incidence than nominal use of the warning system.

Because environmental conditions necessary for high or moderate sporulation occur less often than conditions for high or moderate infection $(18,19)$, fewer sprays were applied in 1990 based solely on sporulation than based solely on infection (Table 1). Number of sprays applied for the sporulation-based treatment was the same or greater than the number applied for the nominal-warning-system treatment over the course of the experiment (Table 1). However, even when the numbers of sprays were the same (e.g., four in 1990), the dates were not the same (data not shown). Mean disease incidence for the sporulation-based treatment was about the same as for the nominal-warning-system treatment in $1990(\sim 7 \%)$, but incidence was higher for the sporulation-based treatment in $1992(\sim 25 \%$ versus $\sim 15 \%)$ (Table 1). Other modifications of the warning system did not result in any clear-cut increase or decrease in final disease incidence (Table 1), even though the number and timing of spray applications varied.

\section{DISCUSSION}

Downy mildew of grapes could be controlled effectively in Ohio with fewer fungicide applications than a standard calendar-based schedule by use of a disease warning system. The nominal use of the warning system resulted in low disease incidence relative to the unsprayed control and similar incidence to that found for the standard fungicide schedule (Table 1). In fact, in some years (1992 and 1995), disease incidence was less in the plots that were sprayed according to the warning system than in plots sprayed every 10 to 14 days. This latter result could be due to differences in the effectiveness of the two fungicides used in the treatments for these years as well as timing of the sprays. High levels of disease control were obtained in years with very high disease incidence in the unsprayed control plots (e.g., 1992 and $1995)$ and years with more moderate levels of disease incidence (e.g., 1994). Even though the starting date for fungicide applications, and thus the number of sprays, varied considerably among years, number of sprays was reduced by 20 to $75 \%$ over 7 years, with a median reduction of $55 \%$.

Although the warning system generally resulted in low disease incidence, there is evidence that the system can be improved. For instance, no diseased leaves were ob- served in any treatment plot in 1991 and 1993, but the system recommended three to four fungicide applications each year (Table 1). There are, obviously, many reasons why a disease warning system may result in more fungicide applications than needed $(4,21)$. We feel the most likely reason for this excessive number of sprays with the downy mildew system was that overwintering of the oospores and their maturation in the spring were ignored. Thus, we speculate that there was little initial inoculum in 1991 and 1993. Tran Manh Sung et al. (29) showed that oospore maturation is variable among years and strongly influenced by climate. Park et al. $(25,26)$ and Magery et al. (23) incorporated this component and explicitly considered primary and secondary infections in their more detailed warning systems. Their systems are most appropriate for $V$. vinifera and highly susceptible hybrids. Based on our results, downy mildew could be controlled in some years in Ohio with even fewer fungicide applications than used here if primary infection was accurately predicted. Even without a component to predict initial inoculum, as shown here, following warning-system advisories still aids in reducing number of sprays relative to the standard schedule.

Simplifications of the downy mildew warning system, such as spraying based only on the risk of infection or sporulation, can also result in reduced disease incidence relative to unsprayed controls. In addition to the work presented here, Gadoury et al. (12) found that effective control of downy mildew could be achieved in New York when protectant fungicides were applied during the second half of growing seasons based on predicted high sporulation by this disease warning system. Furthermore, Gaduory et al. (12) found that the first symptoms of downy mildew on leaves in New York were found 4 to 7 days after an infection period predicted by the Lalancette et al. model (19). Although acceptable disease control could be achieved in the current study when only individual components of the warning system were considered (Table 1), more fungicide applications were needed to achieve this level of control because more days were identified that were favorable (based on the models) for one of these components (e.g., infection or sporulation) compared with the nominal use of the warning system, in which sporulation, spore survival, and infection were all considered.

Based on results here, simplifications could be considered to facilitate the use of this warning system by growers. The simplest approach would be to ignore environmental conditions entirely and spray a fungicide such as metalaxyl relatively few times at specific growth stages. Since the nominal use of the warning system resulted in three or four sprays in all years except 1989, it should be determined if three or 
four sprays, applied starting at bloom (12), can result in satisfactory control in Ohio and other midwestern states. We predict that this approach would not attain the control found here because of mistiming of the sprays. However, the level of control may be sufficient, especially in drier growing seasons, if other cultural practices are taken to reduce inoculum levels $(7,10,12)$. An approach based on calendar or growth stage would have the advantage of being easily integrated into a management program for all grape diseases and pests $(7,9-11)$.

One advantage of multicomponent warning systems, such as the one tested here, is that they allow specific monocyclic processes to be targeted with the appropriate fungicide type. This type of targeting can be achieved when model outputs are used in conjunction with local weather forecasts, as done by SkyBit Inc. (State College, PA) (13). For example, the sporeload component of the warning system provides an indication of the potential risk of inoculum to infection at any given time during the growing season. If the prediction is for a high spore load and rainfall is forecast, then a protectant fungicide can be applied in advance of the potential infection period. However, if the spore load is not currently high or the forecast for rain is less definite, then one can wait for the model to evaluate the period of leaf wetness. Then, if the model indicates that infection was likely, a fungicide with postinfection capability could be applied. In essence, this approach utilizes information on fungicide capabilities, as well as optimum timing of sprays, to achieve maximum control with the fewest applications.

\section{ACKNOWLEDGMENTS}

Salaries and support provided by state and federal funds (especially grants from the Ohio Grape Industries Program) appropriated to the Ohio Agricultural Research and Development Center, The Ohio State University, Wooster.

\section{LITERATURE CITED}

1. Anonymous. 1993. Grape Downy Mildew Model User Documentation, Version 2.0. Neogen Corp., Lansing, MI.

2. Blaeser, M., and Weltzien, H. C. 1978. Die Bedeutung von Sporangienbildung, -ausbreitung und -keimung fur die Epidemiebildung von Plasmopara viticola. Z. Pflanzenkr. Pflanzenschutz. 85:155-161.

3. Blaeser, M., and Weltzien, H. C. 1979. Epidemiologische Studien an Plasmopara viti- cola zur Verbesserung der Spritzterminbestimmung. Z. Pflanzenkr. Pflanzenschutz. 86:489-498.

4. Campbell, C. L., and Madden, L. V. 1990. Introduction to Plant Disease Epidemiology. John Wiley \& Sons, New York.

5. Collett, D. 1991. Modelling Binary Data. Chapman \& Hall, London.

6. Cortesi, P., and Hill, G. K. 1994. Simulation of grapevine downy mildew epidemics and control with P.R.O. model. Pages 74-81 in: Proc. Int. Workshop Grapevine Downy Mildew Modeling, 1st. D. M. Gadoury and R. C. Seem, eds. N.Y. Agric. Exp. Stn. Spec. Rep. 68.

7. Ellis, M. A. 1995. Integrated Pest Management (IPM) Disease Management Guidelines for Grapes in Ohio. Ohio State Univ., Dep. Plant Pathol. Ser. 96.

8. Ellis, M. A., Madden, L. V., and Lalancette, N. 1994. A disease forecasting program for grape downy mildew in Ohio. Pages 92-95 in: Proc. Int. Workshop Grapevine Downy Mildew Modeling, 1st. D. M. Gadoury and R. C. Seem, eds. N.Y. Agric. Exp. Stn. Spec. Rep. 68.

9. Ellis, M. A., Madden, L. V., and Wilson, L. L. 1986. Electronic grape black rot predictor for scheduling fungicides with curative activity. Plant Dis. 70:938-940.

10. Funt, R. C., Ellis, M. A., and Welty, C. 1997. Midwest Small Fruit Pest Management Handbook. Ohio State Univ. Ext. Bull. 861.

11. Gadoury, D. M. 1993. Management of multiple pests in fruit production. Plant Dis. 77:299-302.

12. Gadoury, D. M., Pearson, R. C., Seem, R. C., and Park, E. W. 1997. Integrating the control programs for fungal diseases of grapevine in the northeastern United States. Vitic. Enol. Sci. 52:140-147.

13. Gleason, M. L., Parker, S. K., Pitblado, R. E., Latin, R. X., Speranzini, D., Hazzard, R. V., Maletta, M. J., Cowgill, W. P., Jr., and Biederstedt, D. L. 1997. Validation of a commercial system for remote estimation of wetness duration. Plant Dis. 81:825-829.

14. Healy, M. J. R. 1988. GLIM: An Introduction. Clarendon Press, Oxford.

15. Hughes, G., and Madden, L. V. 1995. Some methods allowing for aggregated patterns of disease incidence in the analysis of data from designed experiments. Plant Pathol. 44:927943.

16. Hughes, G., Madden, L. V., and Munkvold, G. P. 1996. Cluster sampling for disease incidence data. Phytopathology 86:132-137.

17. Kassenmeyer, H. H. 1994. Experience with electronic warning of downy mildew of grapevine. Pages 80-81 in: Proc. Int. Workshop Grapevine Downy Mildew Modeling, 1st. D. M. Gadoury and R. C. Seem, eds. N.Y. Agric. Exp. Stn. Spec. Rep. 68.

18. Lalancette, N., Ellis, M. A., and Madden, L. V. 1987. Estimating infection efficiency of Plasmopara viticola on grape. Plant Dis. 71:981-983.

19. Lalancette, N., Ellis, M. A., and Madden, L.
V. 1988. Development of an infection efficiency model for Plasmopara viticola on American grape based on temperature and duration of leaf wetness. Phytopathology 78:794-800.

20. Lalancette, N., Madden, L. V., and Ellis, M. A. 1988. A quantitative model for describing the sporulation of Plasmopara viticola on grape leaves. Phytopathology 78:1316-1321.

21. Madden, L. V., and Ellis, M. A. 1988. How to develop disease forecasters. Pages 191-208 in: Experimental Techniques in Plant Disease Epidemiology. J. Kranz and J. Rotem, eds. Springer-Verlag Publishers, Berlin.

22. Madden, L. V., Hughes, G., and Ellis, M. A 1995. Spatial heterogeneity of the incidence of grape downy mildew. Phytopathology 85:269-275.

23. Magery, P., Wachtel, M. F., Weir, P. C., and Seem, R. C. 1994. A computer-based simulator for rational management of grapevine downy mildew (Plasmopara viticola). Pages 82-91 in: Proc. Int. Workshop Grapevine Downy Mildew Modeling, 1st. D. M. Gadoury and R. C. Seem, eds. N.Y. Agric. Exp Stn. Spec. Rep. 68

24. Moore, D. F. 1987. Modelling the extraneous variance in the presence of extra-binomial variation. Appl. Stat. 36:8-14.

25. Park, E. W., Seem, R. C., Gadoury, D. M., and Pearson, R. C. 1997. DMCAST: A prediction model for grape downy mildew development. Vitic. Enol. Sci. 52:182-189.

26. Park, E. W., Seem, R. C., Pearson, R. C., and Gadoury, D. M. 1994. DMCAST: A forecasting model for grape downy mildew development. Pages 96-102 in: Proc. Int. Workshop Grapevine Downy Mildew Modeling, 1st. D M. Gadoury and R. C. Seem, eds. N.Y. Agric. Exp. Stn. Spec. Rep. 68.

27. Pearson, R. C., and Goheen, A. C., eds. 1988 Compendium of Grape Diseases. American Phytopathological Society, St. Paul, MN.

28. Stryzik, S. 1983. Modele d'etat potential d'infection: Application a Plasmopara viticola. Association de Co-ordination Technique Angricole, Maison Nationale des Eleveurs, Paris. pp. 1-46.

29. Tran Manh Sung, C., Strizyk, S., and Clerjeau, M. 1990. Simulation of the date of maturity of Plasmopara viticola oospores to predict the severity of primary infections in grapevine. Plant Dis. 74:120-124.

30. Travis, J., Muza, A., Daskopoulos, D., Pearson, R. C., Gadoury, D. M., Becker, C., Ellis, M. A., and Ramsdell, D. 1994. VITIS, a grape disease management expert system. Pages 103-107 in: Proc. Int. Workshop Grapevine Downy Mildew Modeling, 1st. D. M. Gadoury and R. C. Seem, eds. N.Y. Agric. Exp. Stn. Spec. Rep. 68

31. Vercesi, A., Cortesi, P., Zerbetto, F., and Bisiach, M. 1994. Evaluation of the EPI model for downy mildew of grapevine in Northern Italy. Pages 55-73 in: Proc. Int. Workshop Grapevine Downy Mildew Modeling, 1st. D. M Gadoury and R. C. Seem, eds. N.Y. Agric. Exp. Stn. Spec. Rep. 68. 